\title{
The first 20 years of the Canadian Respiratory Journal
}

$\mathrm{T}^{\mathrm{h}}$ he November/December 2013 issue of the Canadian Respiratory Journal heralded the completion of 20 years of publication... a significant feat for all concerned.

There was little Internet in 1993, the use of personal computers was in its infancy, Bill Clinton was President of the United States and Jean Chretien had recently won the election in Canada. It was also the year we approached the President of the Canadian Thoracic Society (CTS), Dr David Cotton, about starting the Canadian Respiratory Journal and asked if he would be interested in becoming the Editor-inChief. He was extremely supportive but also very busy and, although he offered his support, he was unable to take on the post of Editor-inChief. Eventually, Dr Norman Jones, then at McMaster University (Hamilton, Ontario) agreed to take on this important role. Dr Cotton sent a questionnaire to the membership and the majority favoured the adoption of this Journal as its official publication. Dr Yvon Cormier, the CTS president after Dr Cotton, wrote a note in the premiere issue along with Dr Jones. To view this interesting read, refer to www. pulsus.com and the Journal's first issue.

Launching a peer review journal in Canada has always been a difficult task; however, we had successfully launched three publications and knew what to expect. Although we heard from researchers that Canada was too small to have its own journal, many smaller countries have their own journals in this field. We heard "Why should I send my manuscripts to your journal if I can publish in Chest?" However, the majority of (especially) young Canadian researchers did not get their papers accepted by 'big' American journals. We heard from advertising agencies, "Why should I advertise in this journal if I don't understand what it says?" Despite all of this, we were convinced that we had both the leadership and national pride required to launch and support a Canadian journal.

There was a dedicated group of CTS members who worked with our team of Janet O'Flaherty, who now heads a publishing team at the British Medical Association, and John Weller, who organized this Journal's launch. Advertisers also understood that supporting research through advertising made sound economic sense, and the premiere issue was published in March 1994. Dr Jones retired in 2002 and Dr Nick Anthonisen assumed the role of Editor-in-Chief from 2002 to 2011. Dr Peter Paré then took over leadership and that brings us to the present time.

Since 1994, we have published hundreds of excellent articles in issues, in supplements, in print and online. We have launched a website and are in the process of developing apps for mobile devices. The Journal is indexed everywhere and has, by Canadian standards, a relatively high impact factor. Financially, this Journal has had some good years and many challenging ones, with consistent advertising being somewhat elusive. Each year, we have provided the Journal free of charge to more than 10,000 Canadian physicians, serving as an important tool for knowledge translation for the CTS and, in addition, Pulsus has paid a percentage of revenues to the Society. We acknowledge and are appreciative of the CTS' consistent efforts to support the Journal and their commitment to pay for extra pages in the Journal to publish guidelines and special articles. Without this support, the timeline to publication of studies awaiting publication would have been extended significantly. Frankly, it also assured the Journal's survival during challenging times.

We don't need to tell you that the landscape for publishing has changed dramatically since the early 1990s. The recent Pharmaceutical Advertising Advisory Board-driven change to remove the requirement for printed prescribing information has had a significant impact on the Canadian medical publishing industry. At the same time, there is increased pressure from authors to have their research available open access immediately. We have, therefore, developed an option that will allow researchers to pay (per published page) to have their material published open access as quickly as possible following acceptance. It should be noted that this material will not be given priority over articles awaiting publication but rather will be published in addition to the regular material.

Our projection for the Journal in 2014 is currently very positive given the planned product launches. Eventually, however, we must all prepare for the day that advertising will no longer be sufficient to support the Journal all by itself and we will need to move to a hybrid model of industry/author support to thrive. The Canadian Journal of Infectious Diseases $\mathcal{B}$ Medical Microbiology is a fine example (having moved to this model three years ago) of how successful this model can be in securing financial stability.

The Canadian Respiratory Journal has weathered many storms and is here to stay - at least for another 20 years. And here's to all of us for making it happen!

Robert B Kalina Publisher 


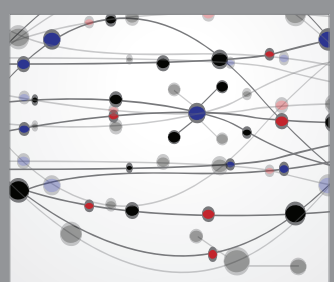

The Scientific World Journal
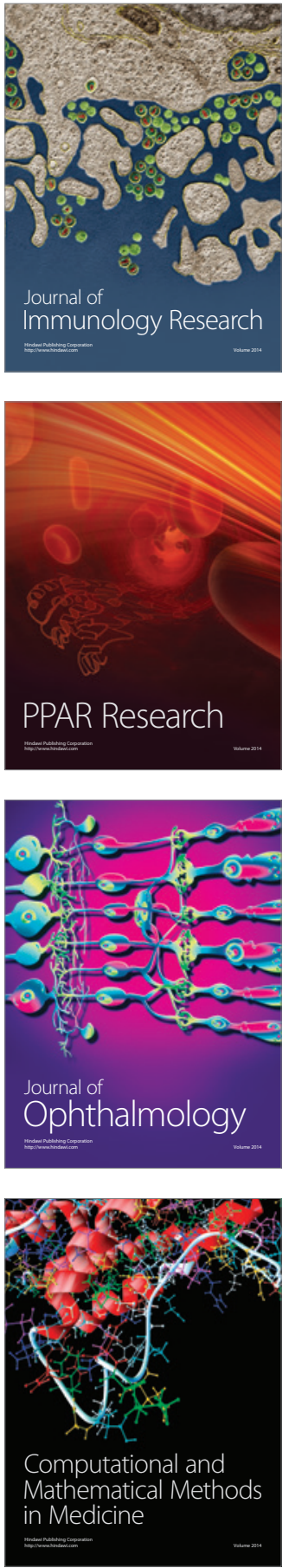

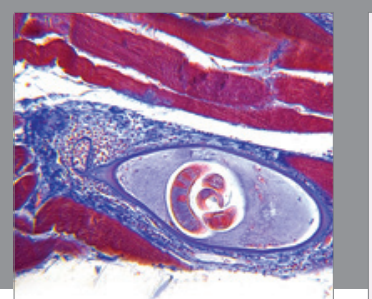

Gastroenterology Research and Practice

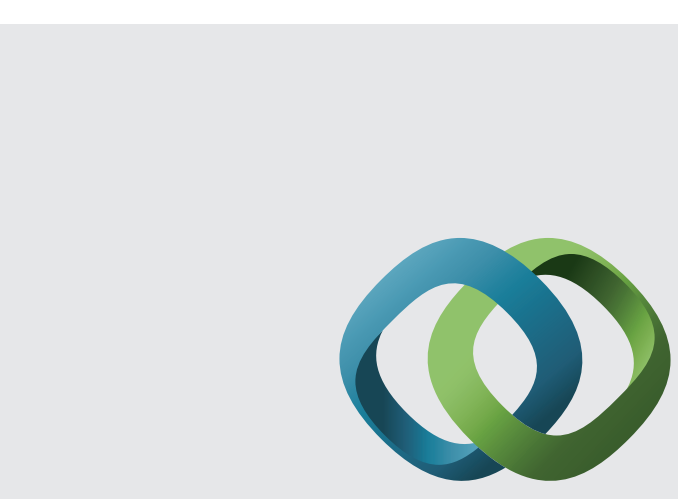

\section{Hindawi}

Submit your manuscripts at

http://www.hindawi.com
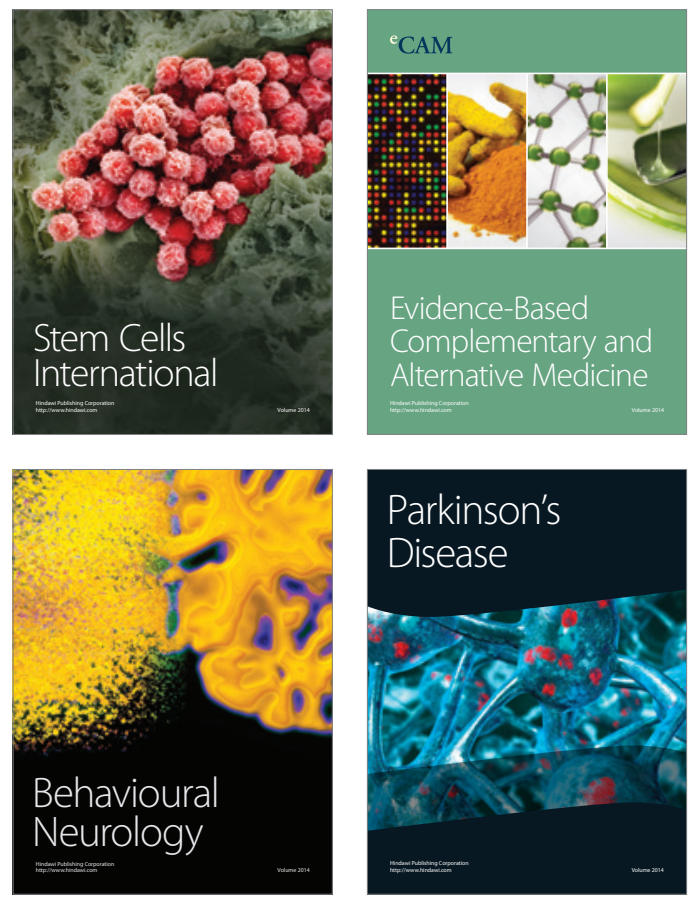
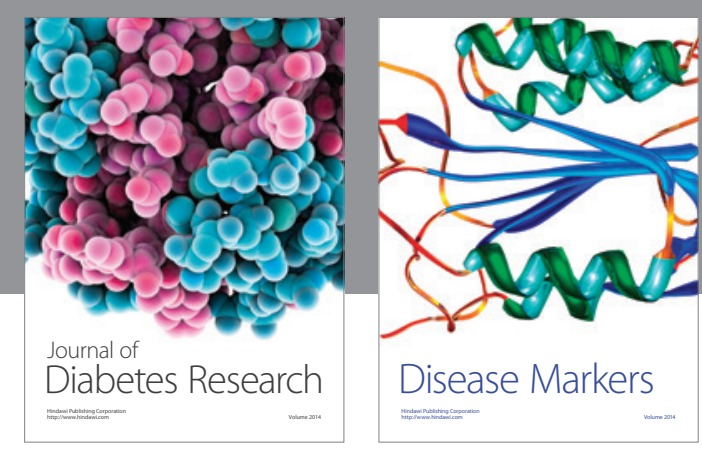

Disease Markers
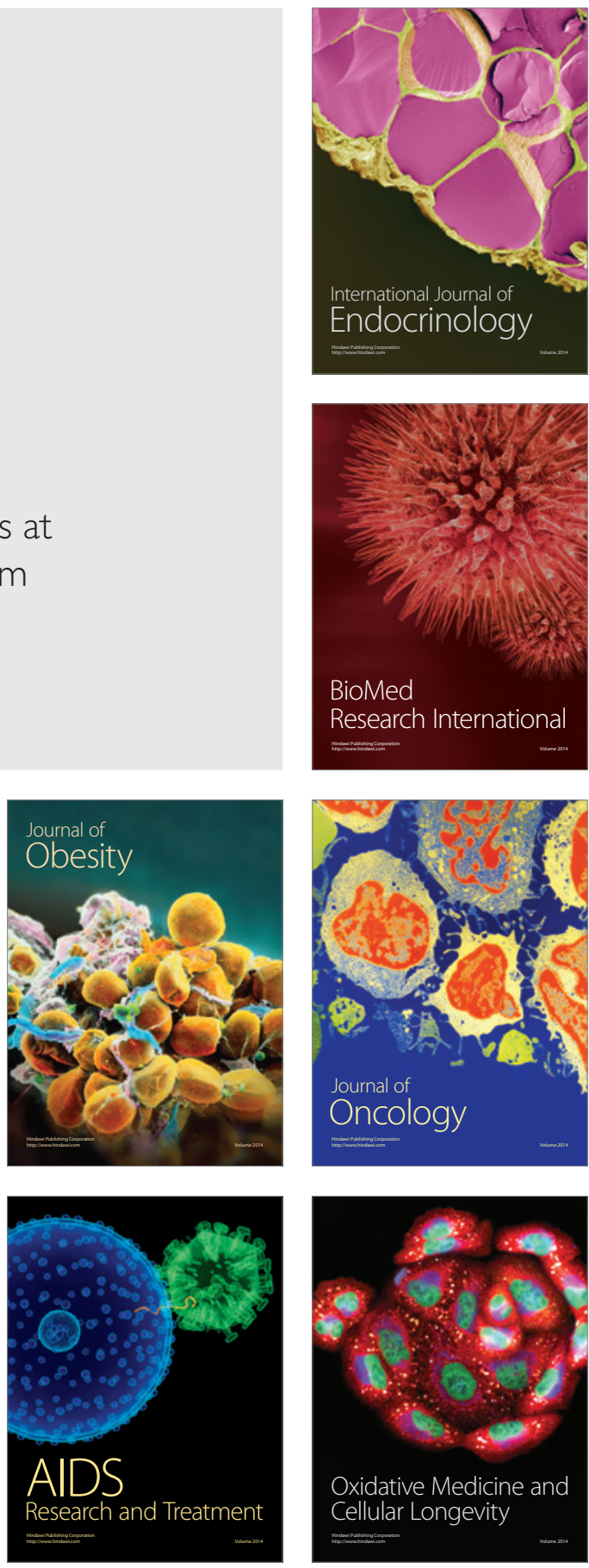